\section{(6) OPEN ACCESS}

\title{
Exacerbation-like respiratory symptoms in individuals without chronic obstructive pulmonary disease: results from a population-based study
}

\author{
W C Tan, ${ }^{1}$ J Bourbeau, ${ }^{2}$ P Hernandez, ${ }^{3}$ K R Chapman, ${ }^{4}$ R Cowie, ${ }^{5}$ J M FitzGerald, ${ }^{6}$ \\ D D Marciniuk, ${ }^{7}$ F Maltais, ${ }^{8}$ A S Buist, ${ }^{9}$ D E O'Donnell, ${ }^{10}$ D D Sin, ${ }^{1}$ S D Aaron, ${ }^{11}$ \\ for the CanCOLD Collaborative Research Group
}

\begin{abstract}
- Additional material is published online only. To view please visit the journal online (http://dx.doi.org/10.1136/ thoraxjn-2013-205048)

For numbered affiliations see end of article.
\end{abstract}

\section{Correspondence to} Dr Wan C Tan, UBC James Hogg Research Centre, Providence Heart + Lung Institute, University of British Columbia, St Paul's Hospital, Rm 166, 1081 Burrard Street, Vancouver, British Columbia, Canada V6Z 1Y6: wan.tan@hli.ubc.ca

Received 20 December 2013 Revised 3 March 2014 Accepted 12 March 2014 Published Online First 4 April 2014

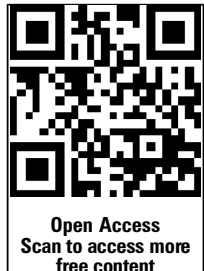

\section{SLinked}

- http://dx.doi.org/10.1136/ thoraxjnl-2014-205889

- http://dx.doi.org/10.1136/ thoraxjnl-2014-205763

\begin{abstract}
Rationale Exacerbations of COPD are defined clinically by worsening of chronic respiratory symptoms. Chronic respiratory symptoms are common in the general population. There are no data on the frequency of exacerbation-like events in individuals without spirometric evidence of COPD.

Aims To determine the occurrence of 'exacerbation-like' events in individuals without airflow limitation, their associated risk factors, healthcare utilisation and social impacts.

Method We analysed the cross-sectional data from 5176 people aged 40 years and older who participated in a multisite, population-based study on lung health. The study cohort was stratified into spirometrically defined COPD (post-bronchodilator $\mathrm{FEV}_{1} / \mathrm{FVC}<0.7$ ) and non-COPD (post bronchodilator $\mathrm{FEV}_{1} / \mathrm{FVC} \geq 0.7$ and without self-reported doctor diagnosis of airway diseases) subgroups and then into those with and without respiratory 'exacerbation-like' events in the past year.

Results Individuals without COPD had half the frequency of 'exacerbation-like' events compared with those with COPD. In the non-COPD group, the independent associations with 'exacerbations' included female gender, presence of wheezing, the use of respiratory medications and self-perceived poor health. In the non-COPD group, those with exacerbations were more likely than those without exacerbations to have

\section{Key messages}

What is the key question?

- This population-based multicentre study investigated acute respiratory exacerbations in subjects with persistent respiratory symptoms but without spirometric evidence of COPD or asthma or a history of diagnosed obstructive lung disease. The study evaluated associated risk factors and health-related and social outcomes associated with exacerbation-like events in these subjects.

What is the bottom line?

- The results showed that acute worsening of respiratory symptoms can occur in subjects without COPD or asthma, that they are associated with identifiable risk factors and that they have a significant health and social impact.

Why read on?

- Events similar to exacerbations of COPD can occur in individuals without spirometric evidence of COPD or asthma. These events may increase the respiratory burden in the community and possibly contribute to a false-positive diagnosis of COPD.
\end{abstract} poorer health-related quality of life (12-item Short-Form Health Survey), miss social activities ( $58.5 \%$ vs $18.8 \%$ ), miss work for income (41.5\% vs $17.3 \%$ ) and miss housework (55.6\% vs $16.5 \%$ ), $\mathrm{p}<0.01$ to $<0.0001$. Conclusions Events similar to exacerbations of COPD can occur in individuals without COPD or asthma and are associated with significant health and socioeconomic outcomes. They increase the respiratory burden in the community and may contribute to the false-positive diagnosis of asthma or COPD.

\section{INTRODUCTION}

Exacerbations of COPD and asthma have been extensively studied ${ }^{1-4}$ and form the core targets for implementation strategies in the management of these airway diseases according to international consensus guidelines. ${ }^{5} 6$ Exacerbations in COPD are important because they have a negative impact on quality of life, ${ }^{78}$ increase mortality, ${ }^{9}$ accelerate the decline in lung function ${ }^{10}{ }^{11}$ and incur high societal costs. ${ }^{12}$

The natural history of unexplained chronic respiratory symptoms in the general population is unknown. Epidemiological studies in the general population ${ }^{13-15}$ and in primary care practices ${ }^{16}$ have shown that chronic respiratory symptoms without objective evidence of airflow limitation are relatively common. The most common triggers of exacerbations in COPD are bacterial and viral respiratory tract infections ${ }^{17}{ }^{18}$ which are also the most common respiratory disorders in the general population. ${ }^{19}$

Risk factors for exacerbations in COPD are well recognised $^{20}$ and consist of a history of a previous exacerbation ('exacerbation phenotype') and the presence of severely impaired lung function, though exacerbation of COPD can occur in individuals across all stages of disease severity. ${ }^{2}$ While exacerbations are important health events in 
patients with COPD or asthma, there is no information on whether such exacerbation-like events occur in the absence of chronic airway disease and whether these events have health and economic impact for the affected individuals. Thus, we undertook this study to determine the prevalence of acute worsening of chronic respiratory symptoms (exacerbation-like events) in subjects without spirometrically diagnosed COPD or known diagnosis of chronic airway diseases; the risk factors for these acute events; and whether these events have an impact on health and social outcomes.

\section{SUBJECTS AND METHOD}

The data from 5176 people from the general population aged 40 years and older were evaluated. Data were collected between August 2005 and May 2009 in a large cross-sectional multisite, population-based study on lung health, which constituted the first phase of the Canadian Cohort of Obstructive Lung Disease, CanCOLD study. The sampling strategy and study protocol of the baseline cross-sectional part of the study were the same as those used in the international Burden of Obstructive Lung Disease (BOLD) initiative, full details of which have been published elsewhere. ${ }^{21} 22$

Briefly, random samples of non-institutionalized adults aged 40 years and older in nine urban sites (Vancouver, Montreal, Toronto, Halifax, Calgary, Quebec City, Kingston, Saskatoon and Ottawa) were drawn from census data from Statistics Canada (Survey and Analysis Section; Victoria, British Columbia, Canada) and recruitment was conducted by NRG Research group (Vancouver, British Columbia, Canada) by random telephone digit dialling to identify eligible subjects ${ }^{21} 22$ who were invited to attend a clinic visit to complete intervieweradministered respiratory questionnaires and to perform pre and post bronchodilator spirometry. The overall participation rate was $74 \%$ (range $63-87 \%){ }^{22}$

\section{Definitions}

\section{Chronic respiratory symptoms}

Chronic cough or chronic phlegm was defined as cough or phlegm not occurring during a 'cold' and on most days for as much as 3 months each year for 2 years. Wheezing was the presence of 'episodes of wheezing or whistling in the chest associated with feeling of shortness of breath, in the past 1 year not occurring during a cold'. Breathlessness was defined as 'troubled by shortness of breath when hurrying on the level or walking up a slight hill' (Medical Research Council dyspnoea scale 2 or greater). ${ }^{23}$

\section{Exacerbation-like events}

A validated standardised questionnaire from the BOLD study, ${ }^{21}{ }^{22}$ which included five questions on exacerbation of chronic respiratory symptoms, was administered to all participants (table 1). The study definition for 'exacerbation' was 'a period of worsening of breathing problems that got so bad that it interfered with usual daily activities or caused the individual to miss work'. 'Exacerbation in the past year' was the occurrence of one or more episodes as defined above occurring in the past year.

\section{Outcomes}

Physical component score (PCS) and mental component score (MCS) were computed from the responses to questions in the 12-item Short-Form Health Survey (SF12) using the method of Ware et al. ${ }^{24}$

Work outcomes include 'Unable to work because of breathing problems' in the past year; 'Missed social activities' in past year because of health problem; for income worker: 'Missed work for income' (stopped work for income in past year due to health issues); for homemaker/caregiver: 'miss housework' (stopped performing usual homemaking/care-giving activities in the past year because of health issues).

\section{COPD and non-COPD subgroups}

Study definitions of 'COPD' were derived from the Global Initiative for Obstructive Lung Disease (GOLD) definition for spirometrically defined COPD based on post-bronchodilator $\mathrm{FEV}_{1} /$ FVC $<0.70$. The whole cohort was stratified into 'non-COPD' and 'COPD' subgroups for comparison of the risk of exacerbation. The alternative definition for COPD as $\mathrm{FEV}_{1} / \mathrm{FVC}<5$ th percentile (lower limits of normal (LLN)) was also applied for a supplementary analysis. In the non-COPD subgroup we further excluded subjects with a reported doctor diagnosis of asthma, COPD, emphysema or chronic bronchitis to avoid confounding by preexisting clinically diagnosed chronic airway disease and its management and potential for exacerbations.

A subset of the non-COPD group who also had CT scans of the thorax were assessed to determine potential causes of the chronic respiratory symptoms, such as emphysema or bronchiolitis. Emphysema score was computed by the summation of the scores of the upper, middle and lower zones of right and left lungs on the CT scan using the method described in the COPDGene study. ${ }^{25}$

All participants gave written, informed consent and the study was approved by the respective university and institutional ethical review boards.

\section{Statistical analysis}

All data analyses were performed using statistical software (Statistical Analysis Software, V.9.1; SAS Institute; Cary, North Carolina, USA). All tests were two tailed in nature; we considered a $p$ value of 0.05 or less to be significant.

Only spirometric data that fulfilled the American Thoracic Society (ATS) acceptability and repeatability criteria were used

Table 1 Exacerbation questions from the BOLD Core Questionnaire

19. Have you ever had a period when you had breathing problems that got so bad that they interfered with your usual daily activities or caused you to miss
work?
(If yes, ask Question 19a. If no, skip 19a, 19b,19c,19d)
19.a How many such episodes have you had in the past 12 months?
(If 19a>0, ask Question 19b, 19c, else skip 19b, 19c, 19d)
19.b For how many of these episodes did you need to see a doctor or other healthcare provider in the past 12 months?
19.c For how many of these episodes were you hospitalised overnight in the past 12 months
(If 19c>0, ask Question 19d, else skip 19d)
19.d All together, for how many total days were you hospitalised overnight for breathing problems in the past 12 months?
BOLD, Burden of Obstructive Lung Disease.


for analyses. Descriptive statistics are shown as percentages for categorical data and means and SDs for continuous variables, unless otherwise stated.

Comparisons of demographic, smoking habits, clinical and lung function variables between 'non-COPD' and 'COPD' groups and outcomes between subgroups of those with versus those without exacerbations-like events in the non-COPD group were performed using $\chi^{2}$ tests for dichotomous variables and Kruskal-Wallis tests for continuous variables.

To address the determinants or predictors of ' 1 or more exacerbations in COPD or exacerbation-like events in non-COPD in the past year' multivariable logistic regression analyses (parsimonious and full models) were used to explore associations between demographic variables, respiratory symptoms, comorbidities, reported diagnoses of airway diseases, health-related quality of life scores and the presence of at least one exacerbation in the past year. Adjusted ORs and 95\% CIs were calculated adjusting for all other variables.

\section{RESULTS}

From 5176 participants, 94\% $(n=4890)$ had spirometric data that fulfilled the ATS acceptability and repeatability criteria and were used for stratifying the cohort into COPD (postbronchodilator $\mathrm{FEV}_{1} / \mathrm{FVC}<0.70$ ) and non-COPD (postbronchodilator $\mathrm{FEV}_{1} / \mathrm{FVC} \geq 0.70$ ) subgroups.

\section{Comparison of characteristics between individuals with and without COPD}

Table 2 shows that the non-COPD group (excluding individuals with reported asthma and $\mathrm{COPD} /$ chronic bronchitis/emphysema, $n=673$ ) consisted of 3379 subjects and the COPD group consisted of 838 subjects. Compared with the COPD group, the non-COPD group was younger, consisted of more women, had more never-smokers, included a lower proportion of individuals with chronic respiratory symptoms and respiratory exacerbations, and had higher lung function. Exacerbation-like events within the previous year were reported in 130 of 3379 subjects (3.9\%) without COPD compared with 69 of 838 subjects $(8.2 \%)$ with COPD $(p<0.001)$ (figure 1$)$. The proportions of subjects in the non-COPD versus the COPD group that had chronic respiratory symptoms were as follows: chronic cough (8.4\% vs $22.3 \%)$; phlegm (5.9\% vs $19.3 \%)$; wheezing $(19.1 \%$ vs $45.1 \%)$; breathlessness $(20.6 \%$ vs $38.6 \%)$; all p values < 0.0001 .

\section{Comparison of characteristics between those with exacerbations and those without exacerbations in the non-COPD group}

Individuals in the non-COPD group with exacerbation-like events in the past year had lower $\mathrm{FEV}_{1} \%$ predicted and $\mathrm{FVC} \%$ predicted and were more likely to have chronic respiratory symptoms compared with those without a history of exacerbations (table 3 and figure 2).

\section{Predictors of respiratory exacerbations in individuals with and without COPD}

Table 4 shows the results of the multivariable logistic regression analyses of the risk of exacerbation in the previous year for multiple variables: demographic, clinical, lung function and health status outcome, computed as crude and adjusted OR. The crude OR suggested many risk factors for exacerbation but after adjustment for confounders in the multivariable model, only the female sex, wheezing, reported use of respiratory medications and perceived low health status were independent predictors of exacerbations in the non-COPD subgroup.

Figure 3 shows that COPD and non-COPD subgroups shared common predictors of respiratory exacerbations, but the female gender was unique to non-COPD and severe reduction in $\mathrm{FEV}_{1}$ to individuals with COPD. When the analyses were repeated using the alternative spirometric definition for airway obstruction (post-bronchodilator $\mathrm{FEV}_{1} / \mathrm{FVC}<\mathrm{LLN}$ ), the predictors remained unchanged (results not shown) (see online supplementary table S1).

\section{Healthcare, health status and social impacts of respiratory exacerbations in individuals without COPD}

The proportion of subjects without COPD who experienced an 'exacerbation' was lower compared with the COPD group, but the impact of an individual exacerbation on healthcare utilisation appeared to be equal or greater in this group. From table 2, in the non-COPD group, 89/130 (68\%) exacerbations needed a doctor's visit; in the COPD group, 43/69 exacerbations (62\%) needed a doctor's visit.

In the subgroup of individuals without COPD, the presence of exacerbations in the past year had significant health-related and social impacts. The health-related quality of life scores from the SF12 questionnaire responses were reduced from mean (SD) 52.0 (8.2) (without exacerbations) to mean (SD) 47.6 (11.7) (with exacerbations) for the PCS $(\mathrm{p}=0.0003)$ and from 52.4 (8.8) to 47.1 (11.3) for the MCS $(p<0.0001$; figure 4). Individuals who had exacerbations in the past year compared with those who did not have exacerbations were significantly more likely to have missed social activities (58.5\% vs18.8\%); missed work for income (41.5\% vs $17.3 \%)$; and missed housework $(55.6 \%$ vs $16.5 \%)$ ( $\mathrm{p}<0.01$ to $<0.0001$ ) (figure 5).

Finally, in a small subset $(n=383)$ of individuals without COPD and who had up to date, available CT scans of the thorax, preliminary analysis suggested that emphysema score ${ }^{25}$ was higher in individuals with exacerbation versus those without exacerbation: mean score 0.82 vs $0.32, p=0.0317$ (see online supplementary figure S1).

\section{DISCUSSION}

Our study shows that individuals without a prior diagnosis or lung function evidence of current asthma or COPD can have exacerbation-like episodes and such respiratory exacerbations are not uncommon events in these subjects. There are certain associated risk factors and these are important because they have an impact on personal healthcare resource utilisation, on health status and social and economic outcomes.

The individuals in this population-based study were not preselected as in previous large studies of patients with COPD and the results are likely representative of real events in the population. We attributed the overall low prevalence $(8.2 \%)$ of exacerbations in the COPD group in this study compared with higher rates reported for convenient samples of patients with $\mathrm{COPD}^{2}$ to the predominantly mild and undiagnosed COPD in the general population.

In this study, events of acute worsening of respiratory symptoms in the non-COPD group were similarly defined as exacerbations in individuals with spirometrically confirmed COPD. The finding that 'exacerbation-like' events occurred in subjects without COPD though only half as frequently as in subjects with COPD has, to our knowledge, not previously been reported, even though respiratory symptoms in the general population have been well documented in several epidemiological studies. ${ }^{13-16}$ 
Table 2 Description of demographic and clinical variables in subjects with and without COPD

\begin{tabular}{|c|c|c|c|c|}
\hline & \multirow{3}{*}{$\begin{array}{l}\text { Non-COPD (post } \mathrm{FEV}_{1} / \mathrm{FVC} \geq 0.7 \text { ) } \\
\text { and no DDX asthma/ } \\
\text { emphysema/ chronic bronchitis/ } \\
\text { COPD } \\
\mathrm{N}=3379\end{array}$} & \multicolumn{3}{|c|}{ All COPD (post FEV $1 / F V C<0.7$ ) } \\
\hline & & 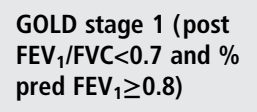 & $\begin{array}{l}\text { GOLD stage } 2 \text { (post } \\
\mathrm{FEV}_{1} / \mathrm{FVC}<0.7 \text { and } \\
0.5 \leq \% \text { pred } \mathrm{FEV}_{1}<0.8 \text { ) }\end{array}$ & $\begin{array}{l}\text { Gold stage } 3-4 \text { (post } \\
\mathrm{FEV}_{1} / \mathrm{FVC}<0.7 \text { and } \% \\
\text { pred } \mathrm{FEV}_{1}<0.5 \text { ) }\end{array}$ \\
\hline & & $\mathrm{N}=465$ & $\mathrm{~N}=315$ & $\mathrm{~N}=58$ \\
\hline \multicolumn{5}{|l|}{ Demographics } \\
\hline Age, mean (SD) & $56.4(10.6)$ & $64.31(11.6)^{*}$ & $64.08(11.2)^{*}$ & $65.97(9.1)^{*}$ \\
\hline Men, n (\%) & $1470(43.5 \%)$ & $246(52.9 \%)^{*}$ & $156(49.5 \%)^{*}$ & $23(39.7 \%)$ \\
\hline BMI, mean (SD) & $27.6(5.6)$ & $26.97(4.5)$ & $28.19(5.8)$ & $29.47(7.5)$ \\
\hline Education, mean (SD) & $15.6(3.4)$ & $15.11(3.9)$ * & $14.23(3.8)^{*}$ & $12.95(4.0)^{*}$ \\
\hline \multicolumn{5}{|l|}{ Smoking of cigarettes } \\
\hline \multicolumn{5}{|l|}{ Smoking status, n (\%) } \\
\hline Never & $1711(50.6 \%)$ & $175(37.6 \%)^{*}$ & $76(24.1 \%)^{*}$ & $8(13.8 \%)^{*}$ \\
\hline Former & $1299(38.4 \%)$ & $211(45.4 \%)^{*}$ & $151(47.9 \%)^{*}$ & $27(46.6 \%)$ \\
\hline Current & $369(10.9 \%)$ & $79(17.0 \%)^{*}$ & $88(27.9 \%)^{*}$ & $23(39.7 \%)^{*}$ \\
\hline Pack years of cigarettes, mean (SD) & $19.8(19.3)$ & $29.96(22.5)^{*}$ & $37.31(27.4)^{*}$ & $49.42(30.5)^{*}$ \\
\hline Passive smoking, $\mathrm{n}(\%)$ & $277(8.2 \%)$ & $66(14.2 \%)^{*}$ & $40(12.7 \%)^{*}$ & $10(17.2 \%)^{*}$ \\
\hline \multicolumn{5}{|l|}{ Exacerbation history, $\mathrm{n}(\%)$} \\
\hline Ever exacerbation & $477(14.1 \%)$ & $94(20.2 \%)^{*}$ & $96(30.5 \%)^{*}$ & $31(53.5 \%)^{*}$ \\
\hline Exacerbation in the past 1 year & $130(3.9 \%)$ & $20(4.3 \%)$ & $32(10.2 \%)^{*}$ & $17(29.3 \%)^{*}$ \\
\hline Exacerbation need to see a doctor in the past 1 year & $89(2.6 \%)$ & $11(2.4 \%)$ & $23(7.3 \%)^{*}$ & $9(15.5 \%)^{*}$ \\
\hline $\begin{array}{l}\text { Exacerbation need to be hospitalised overnight in } \\
\text { the past } 1 \text { year }\end{array}$ & $11(0.3 \%)$ & $2(0.4 \%)$ & $7(2.2 \%)^{*}$ & $2(3.5 \%)^{*}$ \\
\hline \multicolumn{5}{|l|}{ Respiratory symptoms, n (\%) } \\
\hline Chronic cough & $283(8.4 \%)$ & $68(14.6 \%)^{*}$ & $89(28.3 \%)^{*}$ & $30(51.7 \%)^{*}$ \\
\hline Chronic phlegm & $198(5.9 \%)$ & $58(12.5 \%)^{*}$ & $75(23.8 \%)^{*}$ & $29(50 \%)^{*}$ \\
\hline Wheezing & $645(19.1 \%)$ & $155(33.3 \%)^{*}$ & $177(56.2 \%)^{*}$ & $46(79.3 \%)^{*}$ \\
\hline Breathlessness & $658(20.6 \%)$ & $114(26.7 \%)^{*}$ & $136(49.3 \%)^{*}$ & $40(83.3 \%)^{*}$ \\
\hline \multicolumn{5}{|l|}{ Disease and comorbidities, n (\%) } \\
\hline DDX asthma & 0 & $102(21.9 \%)^{*}$ & $96(30.5 \%)^{*}$ & $29(50 \%)^{*}$ \\
\hline DDX emphysema/COPD/chronic bronchitis & 0 & $52(11.2 \%)^{*}$ & $82(26.0 \%)^{*}$ & $34(58.6 \%)^{*}$ \\
\hline Comorbiditiest & $1089(32.2 \%)$ & $216(46.5 \%)^{*}$ & $152(48.3 \%)^{*}$ & $35(60.3 \%)^{*}$ \\
\hline Childhood hospitalisation for breathing problems & $136(4.0 \%)$ & $31(6.7 \%)^{*}$ & $38(12.1 \%)^{*}$ & $3(5.2 \%)$ \\
\hline Use of respiratory medications, $\mathrm{n}(\%)$ & $818(24.2 \%)$ & $162(34.8 \%)^{*}$ & $148(47.0 \%)^{*}$ & $47(81.0 \%)^{*}$ \\
\hline Prescribed medication, (\%) & $(9.1 \%)$ & $(25.0 \%)$ & $(39.9 \%)$ & $(79.3 \%)$ \\
\hline Bronchodilatorł & $(3.3 \%)$ & $(17.6 \%)$ & $(35.2 \%)$ & $(74.1 \%)$ \\
\hline Inhaled steroid‡ & $(7.5 \%)$ & $(18.9 \%)$ & $(29.8 \%)$ & $(69.0 \%)$ \\
\hline Oral steroid $\neq$ & $(0.2 \%)$ & $(0.2 \%)$ & $(1.6 \%)$ & $(1.7 \%)$ \\
\hline Anti-inflammatory (other) $\ddagger$ & $(0.1 \%)$ & $(1.1 \%)$ & $(1.6 \%)$ & $(1.7 \%)$ \\
\hline ОТС§ medication & $(15.1 \%)$ & $(9.8 \%)$ & $(7.1 \%)$ & $(1.7 \%)$ \\
\hline \multicolumn{5}{|l|}{ Quality of life, $\mathrm{n}(\%)$} \\
\hline Self-perceived health status: fair or poor & $251(7.4 \%)$ & $41(8.8 \%)$ & $51(16.2 \%)^{*}$ & $23(39.7 \%)^{*}$ \\
\hline \multicolumn{5}{|l|}{ Pulmonary function } \\
\hline$\% \Delta \mathrm{FEV}_{1} \mathrm{i} \uparrow>12 \%, \mathrm{n}(\%)$ & $116(3.43)$ & $56(12.0 \%)^{*}$ & $84(26.7 \%)^{*}$ & $25(43.1 \%)^{*}$ \\
\hline Post-BD FVC (L), mean (SD) & $3.8(1.0)$ & $4.14(1.1)^{*}$ & $3.28(0.9)^{*}$ & $2.40(0.8)^{*}$ \\
\hline Post-BD FEV 1 (L), mean (SD) & $3.0(0.8)$ & $2.71(0.7)^{*}$ & $1.96(0.6)^{*}$ & $1.04(0.3)^{*}$ \\
\hline Post-BD FEV ${ }_{1} / F V C$, mean (SD) & $79.2(4.7)$ & $65.54(4.1)^{*}$ & $60.01(7.3)^{*}$ & $44.66(11.1)^{*}$ \\
\hline
\end{tabular}

We chose to call acute respiratory worsening in the non-COPD group 'exacerbation-like' events to avoid confusion with the term exacerbations of COPD, even though they were determined using the same criteria that were used to define exacerbations of COPD. ${ }^{1-3}{ }^{26}$ In this study, exacerbation-like events in the non-COPD group and exacerbations in the COPD group share common as well as unique risk factors. The common risk factors for exacerbations consisted of wheezing, poor self perception of health and the use of respiratory drugs in both groups of individuals irrespective of the presence or absence of airflow limitation, while female gender was a unique risk for those without airflow limitation and poor lung function was unique for individuals with COPD. The existence of common risk factors but different frequencies of exacerbations 


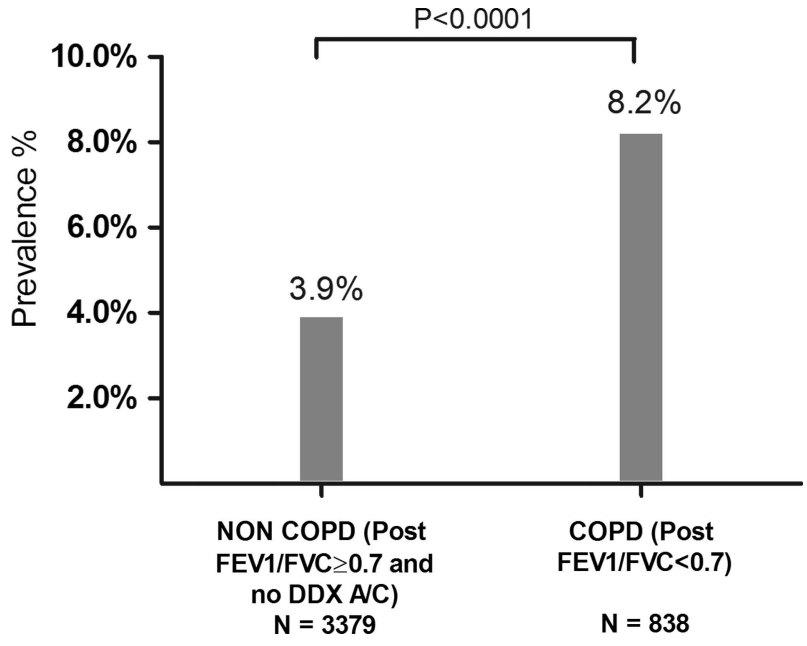

Figure 1 Frequency distribution of proportion of people in non-COPD and COPD groups with exacerbation in the past 1 year (DDX A/C: self-reported doctor's diagnosis of asthma/emphysema/chronic bronchitis/COPD).

for non-COPD and COPD suggest that the frequency of exacerbations could be viewed as a continuum in the general population with common triggers, but different host susceptibilities.

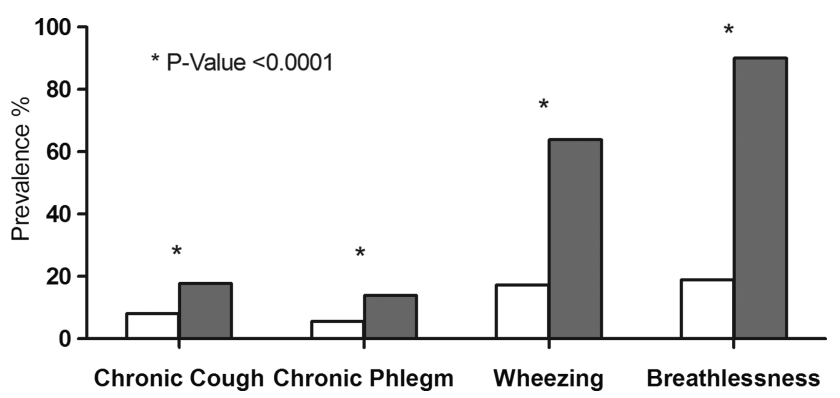

Figure 2 Frequency of chronic respiratory symptoms in 3379 subjects without COPD with and without exacerbation in the past 1 year. Non $\mathrm{COPD}=$ subgroup with post-bronchodilator $\mathrm{FEV}_{1} / \mathrm{FVC}<0.7$ and no self-reported doctor's diagnosis of asthma/emphysema/chronic bronchitis/COPD. Open columns=no exacerbation in the past 1 year; closed columns=exacerbation in the past 1 year.

It is intriguing that female gender was an independent risk factor for exacerbation in individuals without airway disease but not in those with COPD. This may be related to reported increased occurrence of respiratory symptoms, ${ }^{13}{ }^{14}$ but persistence after correction for confounders would suggest a genderspecific susceptibility to exacerbations due to smaller airways or different threshold to symptoms. ${ }^{27}$ It is interesting that the use of respiratory medications was linked to exacerbations in individuals without spirometric or doctor diagnosis of airflow

Table 3 Demographic and clinical characteristics of individuals with exacerbations and those without in the non-COPD group (post-bronchodilator $\mathrm{FEV}_{1} / \mathrm{FVC} \geq 0.7$ and no DDX asthma/emphysema/chronic bronchitis/COPD) subgroups $(n=3379)$

\begin{tabular}{|c|c|c|c|}
\hline & $\begin{array}{l}\text { Did not experience exacerbation } \\
\text { in the past } 12 \text { months }\end{array}$ & $\begin{array}{l}\text { Experienced exacerbation } \\
\text { in the past } 12 \text { months }\end{array}$ & \\
\hline & $\mathrm{N}=3249$ & $\mathrm{~N}=130$ & p Value* \\
\hline \multicolumn{4}{|l|}{ Demographics } \\
\hline Age, mean(SD) & $56.43(10.6)$ & $55.02(10.8)$ & 0.140 \\
\hline Male, n (\%) & $1426(43.9)$ & $44(33.85)$ & 0.024 \\
\hline BMI, mean(SD) & $27.7(5.6)$ & $27.9(5.6)$ & 0.711 \\
\hline Education, mean(SD) & $15.61(3.4)$ & $14.85(3.6)$ & 0.271 \\
\hline \multicolumn{4}{|l|}{ Smoking of cigarettes } \\
\hline \multicolumn{4}{|l|}{ Smoking status, n (\%) } \\
\hline Never & $1588(48.9)$ & $80(61.5)$ & 0.005 \\
\hline Former & $1238(38.1)$ & $61(46.9)$ & 0.043 \\
\hline Current & $350(10.8)$ & $19(14.6)$ & 0.169 \\
\hline Pack years of cigarettes, mean(SD) & $19.88(19.35)$ & $17.6(18.1)$ & 0.302 \\
\hline Passive smoking, $\mathrm{n}(\%)$ & $266(8.19)$ & $11(8.46)$ & 0.911 \\
\hline Worked in dusty job (>1 years), $\mathrm{n}(\%)$ & $826(25.42)$ & $41(31.5)$ & 0.118 \\
\hline \multicolumn{4}{|l|}{ Respiratory symptoms, n (\%) } \\
\hline Chronic cough & $260(8.0)$ & $23(17.7)$ & $<0.001$ \\
\hline Chronic phlegm & $180(5.5)$ & $18(13.9)$ & $<0.001$ \\
\hline Wheezing & $562(17.3)$ & $83(63.9)$ & $<0.001$ \\
\hline Breathlessness & $616(18.96)$ & $117(90.0)$ & $<0.001$ \\
\hline \multicolumn{4}{|l|}{ Pulmonary function } \\
\hline$\% \Delta \mathrm{FEV}_{1} \mathrm{it}>12 \%, \mathrm{n}(\%)$ & $2950(90.8)$ & $115(88.5)$ & $<0.001$ \\
\hline Post-BD FEV $1(\mathrm{~L})$, mean(SD) & $3.00(0.79)$ & $2.84(0.69)$ & 0.011 \\
\hline Post-BD FVC (L), mean(SD) & $3.80(1.02)$ & $3.60(0.86)$ & 0.011 \\
\hline Post-BD \% Predicted FEV ${ }_{1}(\mathrm{~L})$, mean (SD) & $99.09(14.8)$ & $96.92(14.4)$ & $<0.001$ \\
\hline Post-BD \% predicted FVC (L), mean (SD) & $94.16(14.7)$ & $92.69(14.7)$ & 0.001 \\
\hline Post-BD FEV $/$ /FVC, mean (SD) & $79.15(4.7)$ & $79.21(4.7)$ & 0.890 \\
\hline
\end{tabular}


Table 4 Multivariable analyses of predictors of exacerbations in the past 1 year shown as crude and adjusted ORs, in individuals with and without COPD (results shown were from full predictor model $^{*}$ )

\begin{tabular}{|c|c|c|c|c|}
\hline & \multicolumn{4}{|c|}{ Exacerbation in the past 1 year } \\
\hline & \multicolumn{2}{|c|}{$\begin{array}{l}\text { Non-COPD (post } \mathrm{FEV}_{1} / \mathrm{FVC} \geq 0.7 \text { ) and no } \\
\text { DDX asthma/emphysema/chronic } \\
\text { bronchitis/COPD }\end{array}$} & \multicolumn{2}{|c|}{ COPD (post $\mathrm{FEV}_{1} / \mathrm{FVC}<0.7$ ) } \\
\hline & Crude ORs $(95 \% \mathrm{Cl})$ & $\begin{array}{l}\text { Adjusted ORst } \\
(95 \% \mathrm{Cl})\end{array}$ & Crude ORs $(95 \% \mathrm{Cl})$ & $\begin{array}{l}\text { Adjusted ORst } \\
(95 \% \mathrm{Cl})\end{array}$ \\
\hline \multicolumn{5}{|l|}{ Age categories } \\
\hline $40-49$ & 1.00 & 1.00 & 1.00 & 1.00 \\
\hline $50-59$ & 0.75 (0.50 to 1.14$)$ & $0.65(0.41$ to 1.05$)$ & 1.05 (0.45 to 2.48$)$ & 1.17 (0.40 to 3.44$)$ \\
\hline $60-69$ & $0.53(0.31 \text { to } 0.89)^{*}$ & 0.55 (0.30 to 1.01$)$ & 0.85 (0.36 to 1.99$)$ & 0.69 (0.23 to 2.09$)$ \\
\hline 70 and above & 0.78 (0.44 to 1.36$)$ & 0.74 (0.37 to 1.48$)$ & 0.64 (0.27 to 1.52$)$ & 0.52 (0.16 to 1.71$)$ \\
\hline Women (men as ref.) & $1.53(1.06 \text { to } 2.21)^{*}$ & $1.67(1.08 \text { to } 2.56)^{*}$ & 1.37 (0.84 to 2.26$)$ & 1.14 (0.61 to 2.13 ) \\
\hline \multicolumn{5}{|l|}{ BMI categories } \\
\hline$<20$ & $1.57(0.65$ to 3.80$)$ & 1.59 (0.58 to 1.48$)$ & 0.63 (0.08 to 4.99$)$ & 0.79 (0.08 to 7.48$)$ \\
\hline$(20,25)$ & 1.00 & 1.00 & 1.00 & 1.00 \\
\hline$(25,30)$ & 0.97 (0.62 to 1.51$)$ & 0.91 (0.56 to 1.48$)$ & 1.25 (0.65 to 2.42$)$ & 1.07 (0.49 to 2.35$)$ \\
\hline 30 and above & 1.30 (0.83 to 2.03 ) & 0.79 (0.47 to 1.33$)$ & $2.32(1.20 \text { to } 4.46)^{*}$ & 0.92 (0.39 to 2.15$)$ \\
\hline Ever smoking of cigarettes (never as ref.) & $1.67(1.17 \text { to } 2.40)^{*}$ & 1.28 (0.85 to 1.93$)$ & 1.19 (0.69 to 2.07$)$ & 0.58 (0.29 to 1.15$)$ \\
\hline \multicolumn{5}{|l|}{ Pack years of cigarettes } \\
\hline 0 & 1.00 & $\ddagger$ & 1.00 & $\ddagger$ \\
\hline$(0,10)$ & $2.10(1.36 \text { to } 3.26)^{*}$ & $\ddagger$ & $0.16(0.02$ to 1.24$)$ & $\ddagger$ \\
\hline$(10,20)$ & 1.54 (0.88 to 2.70$)$ & $\ddagger$ & 0.85 (0.33 to 2.20$)$ & $\ddagger$ \\
\hline 20 and above & 1.41 (0.87 to 2.26$)$ & $\ddagger$ & 1.57 (0.89 to 2.75$)$ & $\ddagger$ \\
\hline Passive smoking (yes; no as ref.) & 1.04 (0.55 to 1.95$)$ & $\ddagger$ & 0.93 (0.45 to 1.93$)$ & $\ddagger$ \\
\hline Chronic cough (yes; no as ref.) & $2.47(1.55 \text { to } 3.95)^{*}$ & 1.14 (0.63 to 2.06$)$ & $4.18(2.52 \text { to } 6.92)^{*}$ & 1.34 (0.65 to 2.77$)$ \\
\hline Chronic phlegm (yes; no as ref.) & $2.74(1.63 \text { to } 4.61)^{*}$ & 1.82 (0.94 to 3.49$)$ & $3.24(1.93 \text { to } 5.42)^{*}$ & 1.01 (0.47 to 2.15 ) \\
\hline Wheezing (yes; no as ref.) & $8.45(5.84 \text { to } 12.22)^{*}$ & $6.69(4.39 \text { to } 10.21)^{*}$ & $5.98(3.22 \text { to } 11.12)^{*}$ & $2.70(1.25 \text { to } 5.81)^{*}$ \\
\hline Breathlessness (yes; no as ref.) & $2.25(1.52 \text { to } 3.31)^{*}$ & 1.35 (0.86 to 2.13 ) & $3.71(2.07 \text { to } 6.64)^{*}$ & 1.89 (0.90 to 3.96$)$ \\
\hline Self-reported doctor diagnosis of asthma (yes; no as ref.) & $\S$ & $\S$ & $2.39(1.45 \text { to } 3.94)^{*}$ & 0.70 (0.35 to 1.41$)$ \\
\hline $\begin{array}{l}\text { Self-reported doctor diagnosis of emphysema/chronic bronchitis/COPD (yes; } \\
\text { no as ref.) }\end{array}$ & $\S$ & $\S$ & $4.03(2.42 \text { to } 6.69)^{*}$ & 1.65 (0.80 to 3.41$)$ \\
\hline Comorbidities $\uparrow$ (yes; no as ref.) & 1.20 (0.83 to 1.73$)$ & 1.25 (0.78 to 2.01$)$ & $1.20(0.73$ to 1.96$)$ & 1.04 (0.54 to 1.99$)$ \\
\hline Childhood hospitalisation for breathing problem (yes; no as ref.) & 1.60 (0.77 to 3.34 ) & $1.42(0.61$ to 3.30$)$ & $1.68(0.80$ to 3.55$)$ & 0.85 (0.29 to 2.48$)$ \\
\hline Use of respiratory medications (yes; no as ref.) & $2.82(1.98 \text { to } 4.02)^{*}$ & $1.96(1.31 \text { to } 2.94)^{*}$ & $4.65(2.64 \text { to } 8.20)^{*}$ & $2.29(1.08 \text { to } 4.84)^{*}$ \\
\hline Self-perceived health status Fair or poor (excellent/very good/good as ref.) & $3.73(2.40 \text { to } 5.78)^{*}$ & $2.26(1.27 \text { to } 4.02)^{*}$ & $5.76(3.40 \text { to } 9.76)^{*}$ & $2.42(1.19 \text { to } 4.92)^{*}$ \\
\hline \multicolumn{5}{|l|}{ Post-BD FEV $1, \%$ predicted } \\
\hline$>80$ & 1.00 & 1.00 & 1.00 & 1.00 \\
\hline$(50,80)$ & $1.20(0.67$ to 2.16$)$ & $0.60(0.29$ to 1.23$)$ & $2.52(1.41 \text { to } 4.49)^{*}$ & $1.23(0.60$ to 2.51$)$ \\
\hline$<50$ & $\S$ & $\S$ & $9.23(4.48 \text { to } 18.98)^{*}$ & $2.79(1.04 \text { to } 7.53)^{*}$ \\
\hline$\% \Delta \mathrm{FVCi}>12 \%(\leq 12 \% \text { as ref. })^{* *}$ & 0.49 (0.07 to 3.55$)$ & 0.29 (0.03 to 2.66$)$ & 1.11 (0.59 to 2.09$)$ & $0.62(0.25$ to 1.56$)$ \\
\hline$\% \Delta \mathrm{FEV}_{1} \mathrm{i}>12 \%\left(\leq 12 \%\right.$ as ref.) ${ }^{* *}$ & $1.13(0.45$ to 2.82$)$ & 1.10 (0.40 to 3.02 ) & 1.62 (0.93 to 2.83 ) & 1.13 (0.51 to 2.51 ) \\
\hline \multicolumn{5}{|c|}{ 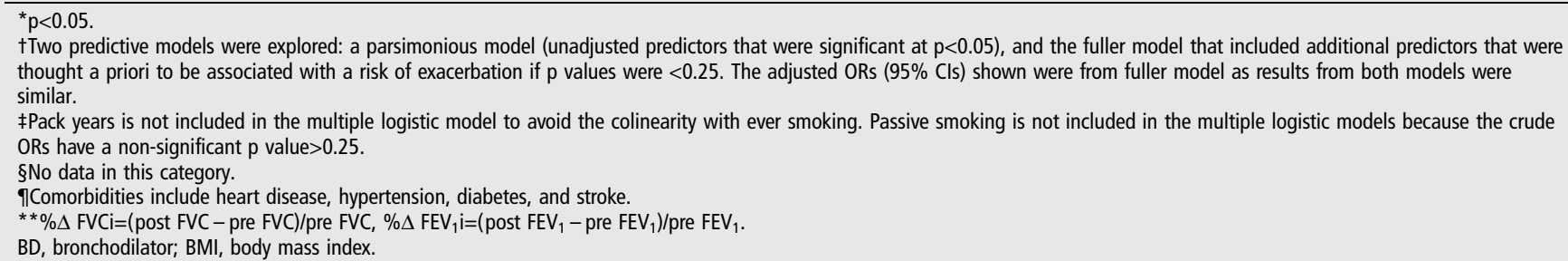 } \\
\hline
\end{tabular}

obstruction. It is unclear from this cross-sectional study whether a self-perceived poor health status was the result or the cause of exacerbations.

An important and novel finding in this study was that respiratory exacerbation-like events in individuals without COPD were associated with distinct health and economic impacts, an observation that had been extensively documented only in patients with COPD. $\begin{array}{lllll} & 2 & 12 & 26 & 28\end{array}$ These individuals were more likely to access healthcare, have poorer health status and loss of economic work, and home and social activities. The impact of these exacerbations in individuals without COPD in this study was not trivial. We estimated that when the percentages of work loss were extrapolated into the Canadian general population of 35 million, over half a million working people lost economic work in the past year and another half a million homemakers had episodes of cessation in housework in the past year. Awareness of this hitherto unrecognised respiratory burden is essential for accurate health economic planning. Studies in 


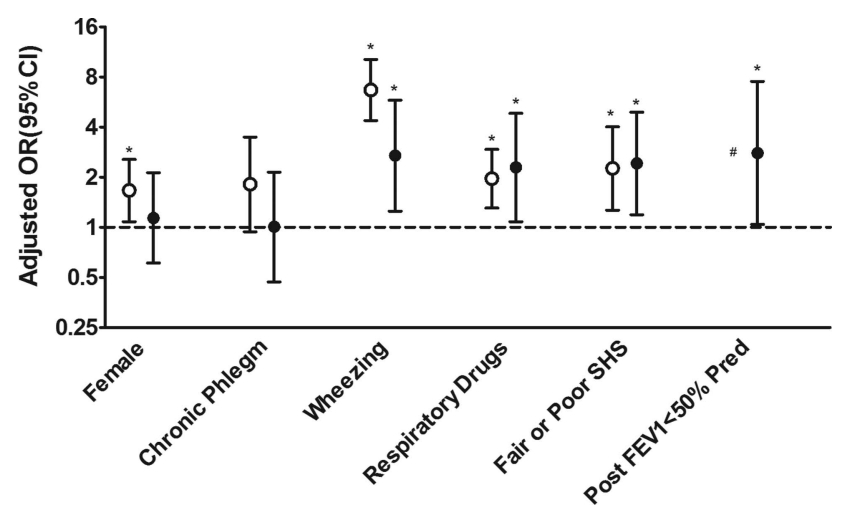

Figure 3 Predictors of exacerbation in the past 1 year in two subgroups of subjects: COPD (post-bronchodilator $\mathrm{FEV}_{1} / \mathrm{FVC}<0.7$ ) and non-COPD (post-bronchodilator $\mathrm{FEV}_{1} / \mathrm{FVC}<0.7$ and no self-reported doctor's diagnosis of asthma/emphysema/chronic bronchitis/COPD). \# For the non-COPD subgroup, the OR for each variable is adjusted for other variables in the figure as well as age, BMl, ever smoking, chronic cough, breathlessness, comorbidities, childhood hospitalisation for breathing problem, and for bronchodilator response after salbutamol (\% change in $\mathrm{FEV}_{1}$ and \% change in FVC.) For the COPD subgroup, additional adjustment included self-reported DDX of asthma, self-reported DDX of emphysema/CB/COPD. Open circles=non-COPD; closed circles=COPD. *Significance is assumed at $p$ value $<0.05$. SHS, self-perceived health status.

primary and tertiary care have suggested a false-positive COPD diagnosis ranging from 30 to $60 \%,{ }^{29} 30$ with consequent longterm therapy with treatments that are not indicated. Exacerbation-like events may lead to a false-positive diagnosis of COPD if spirometry was performed during 'exacerbations'. It is possible that spirometry could be abnormal, as shown by the results of an experimental model of exacerbation in 'healthy' control subjects inoculated with rhinovirus. ${ }^{17}$

There are potential limitations of this study. First, the definition of COPD in this analysis was a challenge. The a priori

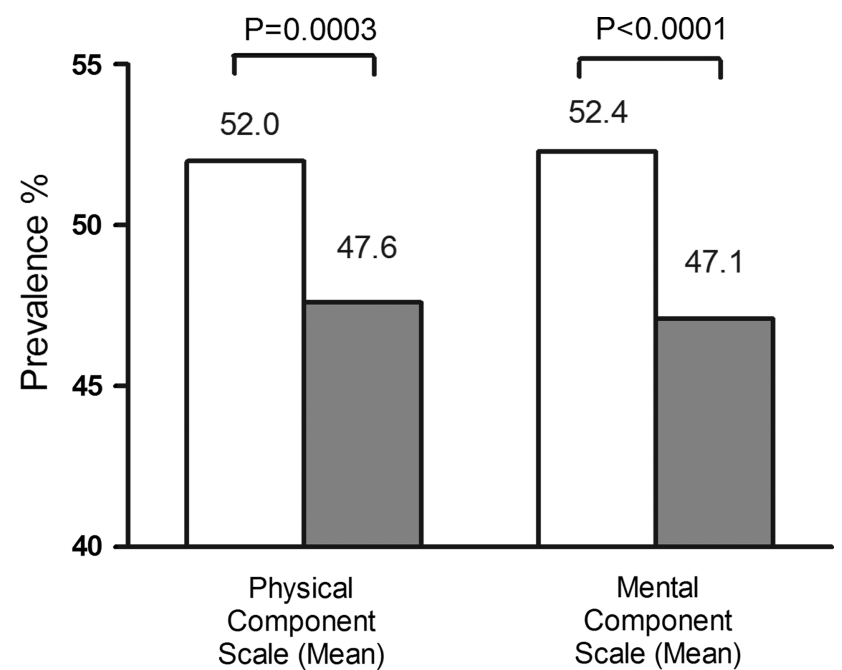

Figure 4 Impact on health-related quality of life ( expressed as physical component scores and mental component scores computed from SF12) in 3379 Non COPD subjects with and without exacerbation in the past 1 year. Non COPD=subgroup with post-bronchodilator FEV1/ FVC $<0.7$ and no self-reported doctor diagnosis of asthma/emphysema/ chronic bronchitis/COPD. Open columns=no exacerbation in the past 1 year; closed columns=exacerbation in the past 1 year.

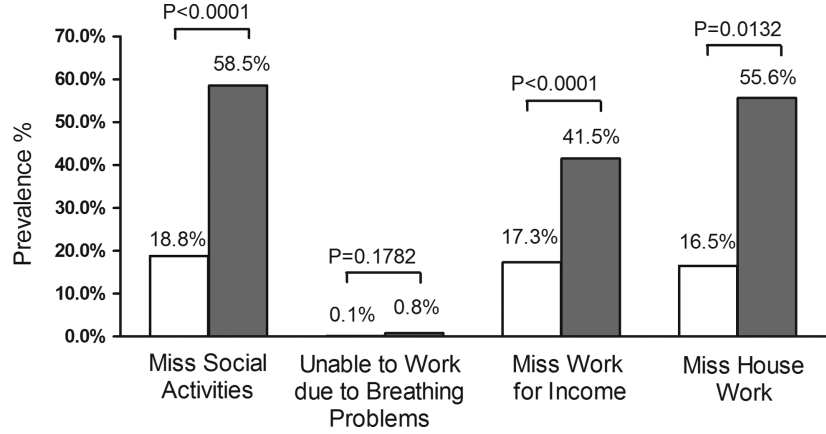

Figure 5 Impact on missing work and missing social activities in the past year in 3379 Non COPD subjects with and without exacerbation in the past 1 year. Non $C O P D=$ subgroup with post-bronchodilator FEV1/FVC $<0.7$ and no self-reported doctor diagnosis of asthma/ emphysema/chronic bronchitis/COPD. Open columns=no exacerbation in the past 1 year; closed columns=exacerbation in the past 1 year.

study definition of post-bronchodilator $\mathrm{FEV}_{1} / \mathrm{FVC}<0.7$ was used for defining COPD versus non-COPD rather than the alternative diagnostic approaches of $\mathrm{FEV}_{1} / \mathrm{FVC}<\mathrm{LLN}$ as we found similar results for demographics, and risk factor associations in a repeat analysis using the alternative definition of $\mathrm{FEV}_{1} /$ FVC $<$ LLN. We also avoided the newer multimodalities GOLD classification ${ }^{4}$ of COPD for patient management, as its applicability in the unselected subjects remains unclear. In the non-COPD subgroup we excluded subjects with a reported doctor's diagnosis of asthma or COPD or emphysema or chronic bronchitis to avoid confounding by pre-existing clinically diagnosed airway disease and its management and potential for exacerbations. We did not challenge individuals in our study with methacholine and cannot rule out the possibility that some of them had mild asthma. In addition, our study definition of exacerbation/'exacerbation-like events' was assessed retrospectively and may be subject to recall bias. Further, the determination of an 'exacerbation' or 'exacerbation-like event' was derived from questions which could not be objectively validated. We did not add antibiotic/prednisolone use as additional criteria to avoid confounding by indication. Hence, such events may not be sufficiently accurate or specific, a problem that had been a challenge for defining exacerbations in COPD studies. ${ }^{1} 326$ Finally, no adjustment was made for multiple comparisons.

Despite these limitations, we were able to show that exacerbations in individuals without COPD were associated with selfperceived health status, healthcare use and social and economic outcomes.

The reasons for 'exacerbations-like events' in individuals without COPD were unclear from this study. Potential explanations include acute respiratory viral infections, ${ }^{17-19} 31$ the most common cause of acute presentation, or worsening of respiratory symptoms and air pollution. ${ }^{32}{ }^{33}$ Other acute conditions such as pneumonia, congestive heart failure, pneumothorax or pulmonary embolism could mimic such exacerbations. ${ }^{1}{ }^{3} 42634$ It is also unknown whether these exacerbation-like events in the non-COPD group have similar onset and recovery patterns to those in patients with COPD. ${ }^{34}{ }^{35}$ It is unlikely that the exacerbations could be explained solely by the presence of chronic bronchitis as chronic cough and chronic phlegm were not independent risk factors for 'exacerbation-like' events in the multivariable analysis. Finally, it is conceivable that we had included patients with undetected asthma, undetected early COPD or emphysema phenotype with relatively well preserved lung function. The possibility of undetected airway disease was suggested 
by the fact that individuals with exacerbations had a lower $\mathrm{FEV}_{1}$ than those without. Further, in a small subset of the non-COPD group who had CT scans of the thorax, an interim univariate analysis showed a higher prevalence of radiologically defined emphysema in those with exacerbations compared with those without exacerbations. However, the number of individuals with exacerbations who had CT scan data was insufficient for accurate statistical analysis and further confirmation would require data from a larger sample in a longitudinal study.

\section{CONCLUSION}

There is a need for increased awareness that exacerbations of respiratory symptoms are not confined to individuals with known obstructive airway diseases. These exacerbations have an important healthcare and economic impact, with public health and health policies implications. We need better means of detecting COPD early as current definitions may not fully capture the true burden of respiratory disease in the population. The presentation of exacerbation-like events may contribute to the false-positive diagnosis of COPD in the community and requires further study. Future studies of the impact of exacerbations in patients with COPD should take into account the occurrence of similar exacerbations in individuals without COPD.

\section{Author affiliations}

'UBC James Hogg Research Center, Providence Heart + Lung Institute, St Paul's Hospital, University of British Columbia, Vancouver, British Columbia, Canada ${ }^{2}$ Respiratory Epidemiology and Clinical Research Unit, Montreal Chest Institute, McGill University, Montréal, Quebec, Canada

${ }^{3}$ Respirology Division, Department of Medicine, QEIl Health Sciences Centre, Dalhousie University, Halifax, Nova Scotia, Canada

${ }^{4}$ Asthma \& Airway Centre, University Health Network and University of Toronto, Toronto, Ontario, Canada

${ }^{5}$ Departments of Medicine and Community Health Sciences, University of Calgary, Calgary, Alberta, Canada

${ }^{6}$ University of British Columbia, Institute for Heart and Lung Health, Vancouver, British Columbia, Canada

${ }^{7}$ Division of Respirology, Critical Care and Sleep Medicine, and Airway research Group, University of Saskatchewan, Saskatoon, Saskatchewan, Canada

${ }^{8}$ Centre de Pneumologie, Institute Universitaire de Cardiologie et de Pneumologie de Québec, Quebec, Canada

${ }^{9}$ Oregon Health and Science University, Portland, Oregon, USA

${ }^{10}$ Division of Respiratory \& Critical Care Medicine, Queen's University, Kingston, Ontario, Canada

${ }^{11}$ Ottawa Hospital Research Institute, University of Ottawa, Ottawa, Ontario, Canada

Acknowledgements COLD/CANCOLD wishes to thank the participants of the study, the funders and collaborators as follows. Funders: the Canadian Institute of Heath Research (CIHR/Rx\&D Collaborative Research Program Operating Grants-93326); industry partners Astra Zeneca Canada, Boehringer-Ingelheim Canada, GlaxoSmithKline Canada, Merck, Novartis Pharma Canada Inc., Nycomed Canada Inc., Pfizer Canada; and the Respiratory Health Network of the FRSQ. Collaborators are listed below.

Collaborators International Advisory Board: Jonathon Samet (the Keck School of Medicine of USC, California, USA), Milo Puhan (John Hopkins School of Public Health, Baltimore, USA), Qutayba Hamid (McGill University, Montreal, QC, Canada); James C Hogg (UBC James Hogg Research Center, Vancouver, BC, Canada). Operations Centers: Jean Bourbeau, Wan C Tan, Carole Jabet, Maria Sedona, Palmina Mancino, Yvan Fortier, Don Sin, Yuexin Li, Sheena Tam, Joe Comeau, Adrian Ng, Harvey Coxson, Tara Candido, Jonathon Leipsic, Cameron Hague, Jeremy Road (University of British Columbia James Hogg Research Center, Vancouver, BC, Canada). Economic Core: Andrea Benedetti (McGill University, Montreal, QC, Canada); Carlo Mara, Mohsen Savafi (University of British Columbia, Vancouver BC). Environmental and public health: Andrea Gershon, Teresa To (University of Toronto). Data management and quality control: Wan C Tan, Harvey Coxson (UBC, Vancouver, BC, Canada); Jean Bourbeau, Zhi L Pei, Denis Jensen (McGill University, Montreal, QC, Canada); Denis O'Donnell (Queen's University, Kingston, ON, Canada). Field centers: Wan C Tan (PI), Christine Lo, Jeong Min, Carly Moy, Anna La Lau, Ashleigh Sran, Ebony Swanson, Ying Yuan, Daniel Chen, Lu Zheng, Tina Yang, Junior Chuang, Best Guo, Licong Li, Kendall Chan, Rahmath Khanam, Daria Maslennikova, Sarah Cheng, Catherine Peng, Bryan Chiang, Sarah Guo, Kyrsten
Payne (UBC James Hogg Research Center, Vancouver, BC, Canada); Jean Bourbeau (PI), Palmina Mancino, Maria Sedona, Carmen Darauay, Myriam Costa (McGill University, Montreal, QC, Canada); Kenneth Chapman (PI), Patricia McClean, Heather Sporn (University of Toronto, Toronto, ON, Canada); Robert Cowie (PI), Ann Cowie, Curtis Dumonceaux, Jessica Moore (University of Calgary, Calgary, AB, Canada); Paul Hernandez (PI), Scott Fulton, Maria Yorke, Natalie Fiorotos, Ashley Rowe (University of Halifax, Halifax, NS, Canada); Shawn Aaron (PI), Kathy Vandemheen, Gay Pratt, Jeevitha Srighanthan (University of Ottawa, Ottawa, ON, Canada); Denis O'Donnell (PI), Kathy Webb, Naparat Amornputtisathaporn, Kate Cheung, Kate Whelan, Jenny Cheng (Queen's University, Kingston, ON, Canada); Francois Maltais (PI), Joanie Couture, Luciana Garcia Pereira, Marie-Josée Breton, Cynthia Brouillard (University of Laval, Quebec City, QC, Canada); Darcy Marciniuk (PI), Ron Clemens, Janet Baran (University of Saskatoon, Saskatoon, SK, Canada).

Contributors WCT contributed to the conception, design of the study, the acquisition of the data, the analysis of the data and the writing. She assembled the dataset and takes responsibility for the integrity of the data and the accuracy of the data analysis. JB, RC, KRC, PH, SDA, DDM, DEO'D, FM contributed to the acquisition of the data and the writing and revision of the article. ASB contributed to the conception, design of the study, and the revision of the article. DDS contributed to the analysis and interpretation of the data and the writing of the article. All authors approved the final version of the manuscript.

Funding The Canadian Cohort of Obstructive Lung Disease (COLD/CanCOLD) is funded by the Canadian Institute of Heath Research (CIHR/Rx\&D Collaborative Research Program Operating Grants 93326); industry partners Astra Zeneca Canada, Boehringer-Ingelheim Canada, GlaxoSmithKline Canada, Merck, Novartis Pharma Canada Inc., Nycomed Canada Inc., Pfizer Canada, and the Respiratory Health Network of the FRSQ. The funders had no role in the study design, data collection and analysis, decision to publish, or preparation of the manuscript.

Competing interests WCT and JB report unrestricted educational grants from GlaxoSmithKline, Pfizer, Boehringer Ingelheim, AstraZeneca for the epidemiological COLD study; grants for the operations of the CanCOLD longitudinal epidemiological study from the Canadian Institute of Heath Research (CIHR/Rx\&D Collaborative Research Program Operating Grants 93326) with industry partners AstraZeneca Canada, Boehringer Ingelheim Canada, GlaxoSmithKline Canada, Merck, Novartis Pharma Canada Inc., Nycomed Canada Inc., Pfizer Canada, outside the submitted work. WCT also received personal fees from GlaxoSmithKline board membership. DO'D reports grants from CIHR Research \& Development during the conduct of the study. DDM, an employee of the University of Saskatchewan, received funding from the Canadian Institutes of Health Research (via McGill University) to undertake this research. KRC received compensation for consulting with CSLBehring, GlaxoSmithKline, Grifols, Novartis, Roche and Takeda; has undertaken research funded by AstraZeneca, Boehringer-Ingelheim, CSLBehring, Forest Labs, GlaxoSmithKline, Johnson \& Johnson, Novartis, Roche and Takeda, and has participated in continuing medical education activities sponsored in whole or in part by AstraZeneca, Boehringer Ingelheim, GlaxoSmithKline, Grifols, Merck Frosst, Novartis, Nycomed, Pfizer and Talecris. PH reports grants from Canadian Institute of Health Research during the conduct of the study; grants and personal fees from AstraZeneca, Boehringer Ingelheim, GlaxoSmithKline, Merck, Novartis, Takeda, Grifols, CSL Behring, Pfizer, Almirall outside the submitted work. FM reports grants from GlaxoSmithKline, Boehringer Ingelheim, other from GlaxoSmithKline, Boehringer Ingelheim, Novartis, Griffols, Almirall, personal fees from Novartis, outside the submitted work. DDS reports personal fees from board membership, grants from/grants pending, personal fees from payment for lectures including service on speakers bureaus, other from travel to Denver for ATS (2011) outside the submitted work. SDA, ASB, JMF and RC have no conflicts of interest to declare.

Ethics approval Institutional review board at each site.

Provenance and peer review Not commissioned; externally peer reviewed.

Data sharing statement Data sharing is available via the CANCOLD process through Dr Wan C Tan (email: wan.tan@hli.ubc.ca) and Dr Jean Bourbeau (email: jean.bourbeau@mcgill.ca).

Open Access This is an Open Access article distributed in accordance with the Creative Commons Attribution Non Commercial (CC BY-NC 3.0) license, which permits others to distribute, remix, adapt, build upon this work non-commercially, and license their derivative works on different terms, provided the original work is properly cited and the use is non-commercial. See: http://creativecommons.org/ licenses/by-nc/3.0/

\section{REFERENCES}

1 Celli BR, Barnes PJ. Exacerbations of chronic obstructive pulmonary disease. Eur Respir J 2007:29:1224-38.

2 Hurst JR, Vestbo J, Anzueto A, et al. Susceptibility to exacerbation in chronic obstructive pulmonary disease. N Engl J Med 2010;363:1128-38.

3 Rodriguez-Roisin R. Toward a consensus definition for COPD exacerbations. Chest 2000:117:3985-401S. 
4 GOLD. Global Strategy for Diagnosis, Management, and Prevention of COPD. Global Initiative for Chronic Obstructive Lung Disease (GOLD) 2011. 2011. http:// www.goldcopd.org/ [accessed 24 Mar 2014].

5 Boulet LP, FitzGerald JM, Levy ML, et al. A guide to the translation of the Global Initiative for Asthma (GINA) strategy into improved care. Eur Respir J 2012;39:1220-9.

6 Jones PW, Nadeau G, Small M, et al. Characteristics of a COPD population categorised using the GOLD framework by health status and exacerbations. Respir Med 2013;108:129-35

7 Kessler R, Stahl E, Vogelmeier C, et al. Patient understanding, detection, and experience of COPD exacerbations: an observational, interview-based study. Chest 2006:130:133-42.

8 Spencer S, Calverley PM, Burge PS, et al. Impact of preventing exacerbations on deterioration of health status in COPD. Eur Respir J 2004:23:698-702.

9 Gunen $\mathrm{H}$, Hacievliyagil SS, Kosar F, et al. Factors affecting survival of hospitalised patients with COPD. Eur Respir J 2005;26:234-41.

10 Donaldson GC, Seemungal TA, Bhowmik A, et al. Relationship between exacerbation frequency and lung function decline in chronic obstructive pulmonary disease. Thorax 2002;57:847-52.

11 Kanner RE, Anthonisen NR, Connett JE. Lower respiratory illnesses promote FEV(1) decline in current smokers but not ex-smokers with mild chronic obstructive pulmonary disease: results from the lung health study. Am J Respir Crit Care Med 2001:164:358-64.

12 Wouters EF. The burden of COPD in The Netherlands: results from the Confronting COPD survey. Respir Med 2003:97(Suppl C):S51-9.

13 de Oca MM, Halbert RJ, Lopez MV, et al. The chronic bronchitis phenotype in subjects with and without COPD: the PLATINO study. Eur Respir J 2012;40:28-36.

14 Lamprecht B, Vanfleteren LE, Studnicka M, et al. Sex-related differences in respiratory symptoms: results from the BOLD Study. Eur Respir J 2013;42:858-60.

15 Tan WC, Bourbeau J, Hernandez P, et al. Bronchodilator responsiveness and reported respiratory symptoms in an adult population. PLOS ONE 2013;8:e58932.

16 Miravitlles M, de la Roza C, Morera J, et al. Chronic respiratory symptoms, spirometry and knowledge of COPD among general population. Respir Med 2006:100:1973-80.

17 Mallia P, Message SD, Gielen V, et al. Experimental rhinovirus infection as a human model of chronic obstructive pulmonary disease exacerbation. Am J Respir Crit Care Med 2010;183:734-42.

18 Sethi S, Murphy TF. Infection in the pathogenesis and course of chronic obstructive pulmonary disease. N Engl J Med 2008;359:2355-65.

19 Graham NM. The epidemiology of acute respiratory infections in children and adults: a global perspective. Epidemiol Rev 1990;12:149-78.
20 Agusti A, Calverley PM, Celli B, et al. Characterisation of COPD heterogeneity in the ECLIPSE cohort. Respir Res 2010;11:122.

21 Buist AS, McBurnie MA, Vollmer WM, et al. International variation in the prevalence of COPD (the BOLD Study): a population-based prevalence study. Lancet 2007:370:741-50.

22 Tan WC, Bourbeau J, FitzGerald JM, et al. Can age and sex explain the variation in COPD rates across large urban cities? A population study in Canada. Int I Tuberc Lung Dis 2011;15:1691-8.

23 Fletcher $\mathrm{CM}$, Elmes PC, Fairbairn AS, et al. The significance of respiratory symptoms and the diagnosis of chronic bronchitis in a working population. $\mathrm{Br}$ Med J 1959;2:257-66.

24 Ware JE Jr, Kosinski M, Keller SD. SF-36 physical and mental health summary scales: a user's manual. Boston: The Health Institute, New England Medical Centre, 1994.

25 Barr RG, Berkowitz EA, Bigazzi F, et al. A combined pulmonary-radiology workshop for visual evaluation of COPD: study design, chest CT findings and concordance with quantitative evaluation. COPD 2012;9:151-9.

26 Wedzicha JA, Brill SE, Allinson JP, et al. Mechanisms and impact of the frequent exacerbator phenotype in chronic obstructive pulmonary disease. BMC Med 2013;11:181.

27 Aryal S, Diaz-Guzman E, Mannino DM. COPD and gender differences: an update. Transl Res 2013;162:208-18.

28 Donaldson GC, Wedzicha JA. Deprivation, winter season, and COPD exacerbations. Prim Care Respir I 2013;22:264-5.

29 Damarla M, Celli BR, Mullerova HX, et al. Discrepancy in the use of confirmatory tests in patients hospitalized with the diagnosis of chronic obstructive pulmonary disease or congestive heart failure. Respir Care 2006;51:1120-4.

30 Starren ES, Roberts NJ, Tahir M, et al. A centralised respiratory diagnostic service for primary care: a 4-year audit. Prim Care Respir J 2012;21:180-6.

31 Seemungal TA, Harper-Owen R, Bhowmik $A$, et al. Detection of rhinovirus in induced sputum at exacerbation of chronic obstructive pulmonary disease. Eur Respir J 2000;16:677-83.

32 Peacock JL, Anderson HR, Bremner SA, et al. Outdoor air pollution and respiratory health in patients with COPD. Thorax 2011;66:591-6.

33 Sint T, Donohue JF, Ghio AJ. Ambient air pollution particles and the acute exacerbation of chronic obstructive pulmonary disease. Inhal Toxicol 2008:20:25-9.

34 Seemungal TA, Donaldson GC, Bhowmik A, et al. Time course and recovery of exacerbations in patients with chronic obstructive pulmonary disease. Am J Respir Crit Care Med 2000;161:1608-13.

35 Aaron SD, Donaldson GC, Whitmore GA, et al. Time course and pattern of COPD exacerbation onset. Thorax 2011:67:238-43. 